\title{
AN UNDERSTANDING OF PLURALITY: A CASE STUDY OF TEACHING AND LEARNING ENGLISH AS AN INTERNATIONAL LANGUAGE (EIL) APPROACH IN AN INDONESIA SENIOR HIGH SCHOOL
}

\author{
${ }^{1}$ Susi Andriani Simanjuntak, ${ }^{2} \mathrm{Hsi}$-Nancy Lien \\ ${ }^{1}$ A Student of International Master Program of Department of Education and Human \\ Potential Development, Hua-Shih College of Education, National Dong Hwa University. \\ ${ }^{2}$ An Associate Professor in Department of Education and Human Potential Development, \\ Hua-Shih College of Education, National Dong Hwa University. \\ Email: $\underline{610688118 @ g m s . n d h u . e d u . t w}$
}

\begin{abstract}
This research is designed to gain an understanding of both English teachers and students' perspectives on English as international language (EIL). There were 6 English teachers and two classes (Grade 1 and Grade 2, approximately with 60 students) were interviewed. We found there is a hegemony concepts about English perspective impart among the students and the teachers in this research community, that is native norm is the center, the most prestigious, endowed with a sense of authenticity and authority. These issues make them afraid to make any risk, little faith to apply EIL that created two different worlds of English standard and nonstandard English. From the result of the study, there are some pedagogical implications of EIL Teaching Approach Contribution in Indonesia. They are EIL teaching required change of mind set in terms of understanding EIL model, the history and English today, and empowering Nonnative English teachers and general Public.
\end{abstract}

Keywords: EIL (English as an international language), Englishes, and Hegemony.

\section{INTRODUCTION}

Englishes is the new image of this current era. It is not a singular noun anymore, English. It becomes plural variation which is embracing the variation of nation English or English variation among languages in the world. Understanding the reality of English nowadays seems contrast with the learning and the teaching English in Indonesia case. I said this because when I was learning English in school as students and my bachelor degree as English teacher training. 
I was taught to teach English with Standard English and honor and adored how great people when we were successful to attain English native like which was seen from our certificate in examination and our spoken as English native like. That image and perspective continuously born and regenerated in my teaching experience included school and English institution where I charged as English teacher. Then, I had a great opportunity to study in Taiwan. I met many international friends from many countries Where English holds a status as a foreign language. During studying and living, I got use to communicate more to nonnative English speakers than native English speakers where less in my university such as Taiwanese, India, Vietnamese, Thailand, Myanmar, Mongolia, Kyrgyzstan, Filipino. I got used to hear broken English till perfect English both of them are legitimate and understandable. Definitely, misunderstanding was inevitable in our communication and negotiation displayed continuously. That was fine and even one of chances to bear fruitful relationship. So I was moving from this point that it was not fair to force Indonesia students to be English user standardly and gave a lot of exposure more to one or two prominent Standard English which ignored their own identity as nonnative English speakers and blinded themselves toward Englishes or global English.

\subsection{Misunderstanding of EIL and the Teaching}

According to Aya Matsuda (2019) there were some fallacies of understanding of the idea and teaching EIL that develop among peoples and they need to clarify in order this is not misleading that make nonnative English users become more and more norm dependent of Native English language. First, the circle of outer and expanding circles essentially learned to communicate with native speakers of the language. However, Teaching EIL to expose learner (NNSs and NSs) to different types of English users that increase the awareness of diversity among English speakers and help learners develop realistic expectations about their future interlocutors. They could meet NNSs in their authentic material as powerful role model and proficient English users, and bringing diverse users of English. Second, English is necessarily learned as a tool to understand and teach American and British cultural values. However, it reflects and now plays an important tool to impact local traditions and cultural values (Kachru, 1992, p.358), and the notion of linguistic nativization, and the process of deculturation (Kachru, 1992) or de-Anglocization (Hino, 2009) to go beyond US and UK. Third, the goal of learning and teaching English is to adopt native models of English or achieve 'native like' character. It suggests that 'native-like' speech is not necessarily the most preferred way of communication because there are legitimate varieties, they are being used and America English or British English may not be the most and the best varieties or assessing the proficiency. 
Fourth, That the native speakers of English as teachers, academic administrators, and material developers provide a serious input in the global teaching of English, in policy formation, and in determining the channels for the spread of the language. The Nonnative English Speaking Teacher (NNESTs) Movement, which started in late 1990s, has deconstructed the notion of NS, recognized the important role that NNESTs played in the profession, and empowered NNESTs through research, teaching, and advocacy work (Selvi, 2014) which shows that NNS practices are legitimate and contribute significantly to the students. The fifth, fallacy is that the diversity and variation in English is necessarily an indicator of linguistic decay and that restricting the decay is the responsibility of the native scholars of English and English Second Language (ESL) programs. However, teaching EIL emphasis the functional appropriateness of languages in sociolinguistic context that diversity and variation in English not an indicator if decay but rather an evidence that is flourishing because they signal the different language use communities across the world and Teaching EIL embraces the diversity and variation of English and attempts to align one selected as instructional model pedagogy with this reality. Those clarifications need to raise awareness that there are possible good cultivation and vice versa cultivation (resistance toward Englishes) ahead through this implementation. Therefore, it needs carefulness, critical thinking, and well plans to achieve the very goals of EIL.

\subsection{Problematizing of EIL and the Teaching in EFL context (Indonesia)}

Widdowson represents the profession as an educator, as a prolific researcher and as an academic administrator. He is active in two professional organizations of the Inner Circle which are extremely influential: The International Association for Teachers of English as a Foreign Language (IATEFL) and the Teaching of English to Speakers of Other Languages (TESOL), and Editors. He raised a number of discussion and consideration which presented as provocation (1995). He started from seeing English as the word of spread itself that it has been spread naturally or by some outside agency or other. If you adopt the second position, it is but a step to argue that the spreading was deliberate, that people conspired to spread it, motivated by colonial ambition.

The students may, and in all probability will, incidentally learn how to use the language for more general purposes as well, for in learning particular actualizations of the virtual language you become aware of its possibilities as a resource for other communication.

But most learners of the language do not have such general purposes in prospect. Their purposes are more specific: to learn a language which enables them to become members of 
expert communities and to communicate with other members wherever they may be and whatever primary culture they come from. They learn the language not to conform to any national norms of general use, but to co-operate as members in international modes of communication. Of course one can argue that the establishment of such international communities has undesirable consequences, that it leads to the privileging of certain groups of people and the neglect of others, that such global purposes act against local interests. But that is a different matter. He thought there is a good deal of substance in such arguments. But they are not arguments against English but against the purposes to which it is put, purposes which, it has to be said, are generally given global approval.

His argument is that the objective for learning English is more appropriately linked to secondary international communities and not primary national ones. Such an argument has to do with the basic rationale for English learning, and concerns matters of educational policy. But it has pedagogic consequences too. Therefore, this idea I thought already taken by our government, Indonesia is the only country in ASEAN which has not made English a compulsory part of the primary curriculum. However, it is commonly taught in primary schools as an optional subject (Siti, 2008). Ministry of Education determines English course formaly start to be taught from junior high school to higher school. Widdowson would suggest that here a more appropriate approach would be one which focuses on the language used in the secondary international communities, those concerned with science, technology, business and so on. This means in effect that English teaching in the general curriculum would be a version of ESP: English for Specific Purposes. This idea also supported by seeing the condition of EFL context. That urged EIL approach also gains problem to learners in developing, resource poor EFL settings especially. As mentioned earlier on page 30, it would be hard for EFL students to learn non-native English variations and by seeing the specific function of learning English for specific purpose which lead to use English more formal and more neutral, and the other part problem is the confusing that the students would face by learning the standard and nonstandard English also a problem. So, from being realistic and, above all, EFL students were not suggested to be producer but consumer centred and thus respectful of the EFL constituency and what it can realistically achieve under difficult conditions.

To sum up, he was trying to say that English teaching should be taught for general purposes and communication and those aims could be achieve in secondary level and it is wrapped in English for specific purposes which imparted in subject matters so they would have concrete learning toward English function for and He suggested to use Standard English version than Englishes because of the EFL context and still dependent on learning English. 
We could say that EIL who embrace standard and nonstandard English was not suggested to implement in EFL countries. From the possible misunderstanding or fallacies of EIL and these criticisms, there are some problematic and conflicts that might arise by introducing and implementing EIL in the actual classroom that we need to aware and consider. Toward this criticism, this might be some discussion to the end how EIL approach contribution to EFL learners and teachers context in an Indonesia senior high school. Therefore, we would like to investigate an understanding of both English teachers and students' perspectives on English as international language (EIL).

\section{METHODOLOGY}

This study presented a case study from one public Senior High Schools Tebing Tinggi. This school is located in Tebing Tinggi where a city of North Sumatra Province, Indonesia. There were approximately 60 students from two grades or classes that I took to engage in this research. They were natural science class from grade 1 and social science class from grade 2 . In this research, In order to achieve triangulation, data were collected from several sources using different collection methods over the period of one month such as interview, actual teaching EIL, classroom observation, and focus group. In this research, there were two sessions of interview. The first interview is for collecting their initial understanding of EIL. During that interview, I gave the students, grade 1 and grade 2, to listen one of English variations from other countries such as Malaysia English, India English, and Hong Kong English to show how global English today is. Then, I was asking their respond about the video that they saw and heard. The second interview was after teaching each lesson. There were three topics so there were three times I interview them to get their experiences, tensions, conflicts, struggle, and challenges EIL teachers and students may experience after teaching and learning of EIL approach in five meetings. There were five teaching sessions and two different interviews (before adapting and after adapting this approach). In teaching session, I transcribed the teaching and learning talks from the video recording and the observation. 
The discourse talk in classroom was examining teacher-students interaction involved emphases, such as examining pupil growth, teacher cognitive styles, mode of interactions, and effect of teacher training of EIL approach. In interview session, that was discourse talk of English teachers and students' talk represents different kinds of talk by different kinds of actors (English teachers and students) to looking at how people constructed meanings and actions through their talk (discourse) in a variety of situation included nonnative speakers, students' and teachers' linguistics and ethnic or racial background, national origins, abilities, and mainstream or public school. So I collected all the data and transcript them all. Then I analyzed them independently by identifying based on the research questions that I wanted to investigate which was to see the students and teachers strengths, opportunity, weaknesses, and threatss so that I could group, adjust, and refine my focus to see the potential and obstacles of adopting EIL approach and second to gain the identity of EFL teachers and students orientation through their discourse talks in the interview. Then, I engaged in recursive reading of the data, coded data segments, categorized them, and identified content. I generated assertions for each theme and looked for best even the confirming and disconfirming cases in order to test the validity of my analysis. The data were transcribed and coded using the coding technique adapted from Auerbach and Silverstein (2003). There were three stages in coding the data: making the text manageable, hearing what was said, and developing theory (Auerbach \& Silverstein, 2003). The first stage, making the text manageable, transcribed the recording, and then referred to identifying the key research areas and main theoretical concepts in the research literature included EIL perspectives of EFL teachers and students.

\section{RESULTS AND DISCUSSIONS}

\subsection{Learning and Teaching EIL Controversies and Possibilities}

From the results, we cultivated that the students learned these topics as knowledge, embracing bright future of learning English, getting to know other peoples and countries, getting good experience with international friends, learning about their own country (transforming, reflecting themselves as Indonesia, proud to be Indonesia), well understanding the function of English, and fulfil the students' needs. The other side, this EIL implementing approach they were found had deficit perspective toward themselves; Moreover, they did not know about Englishes since it was never taught by their teachers, they had bad environment from their community, they also had preferences and avoid Englishes as an error and facilitation and resources from the school as the additional obstacles. The figure below showed 
the students' lack, interest, and values while they were learning EIL approach in their classroom. It could be seen in the figure 1 below.

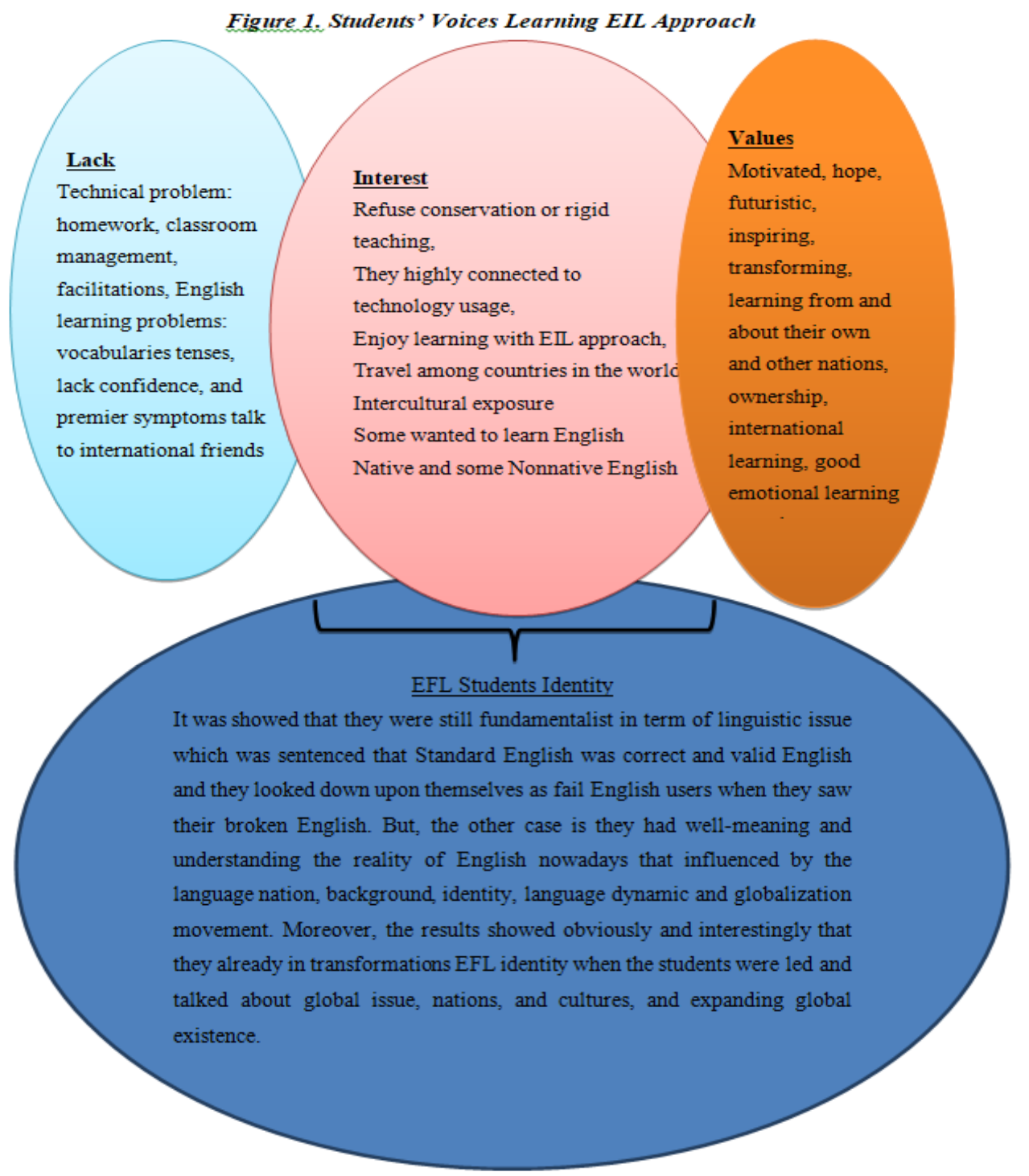

From the teachers' perspective, there were controversial and possibilities of teaching EIL in this school. They welcomed to the nature of English and getting to know EIL approach, well understanding of English as a tool for students' future, and willing to pursue English teaching effectively. The other perspectives that make them hard to implement EIL approach were students' problems, teaching beliefs, preferences, lack of understanding of English variation diversity, curriculum and textbooks. Here is the figure that showed the English teachers' lack, interest, and values while they were learning EIL approach in their classroom. 


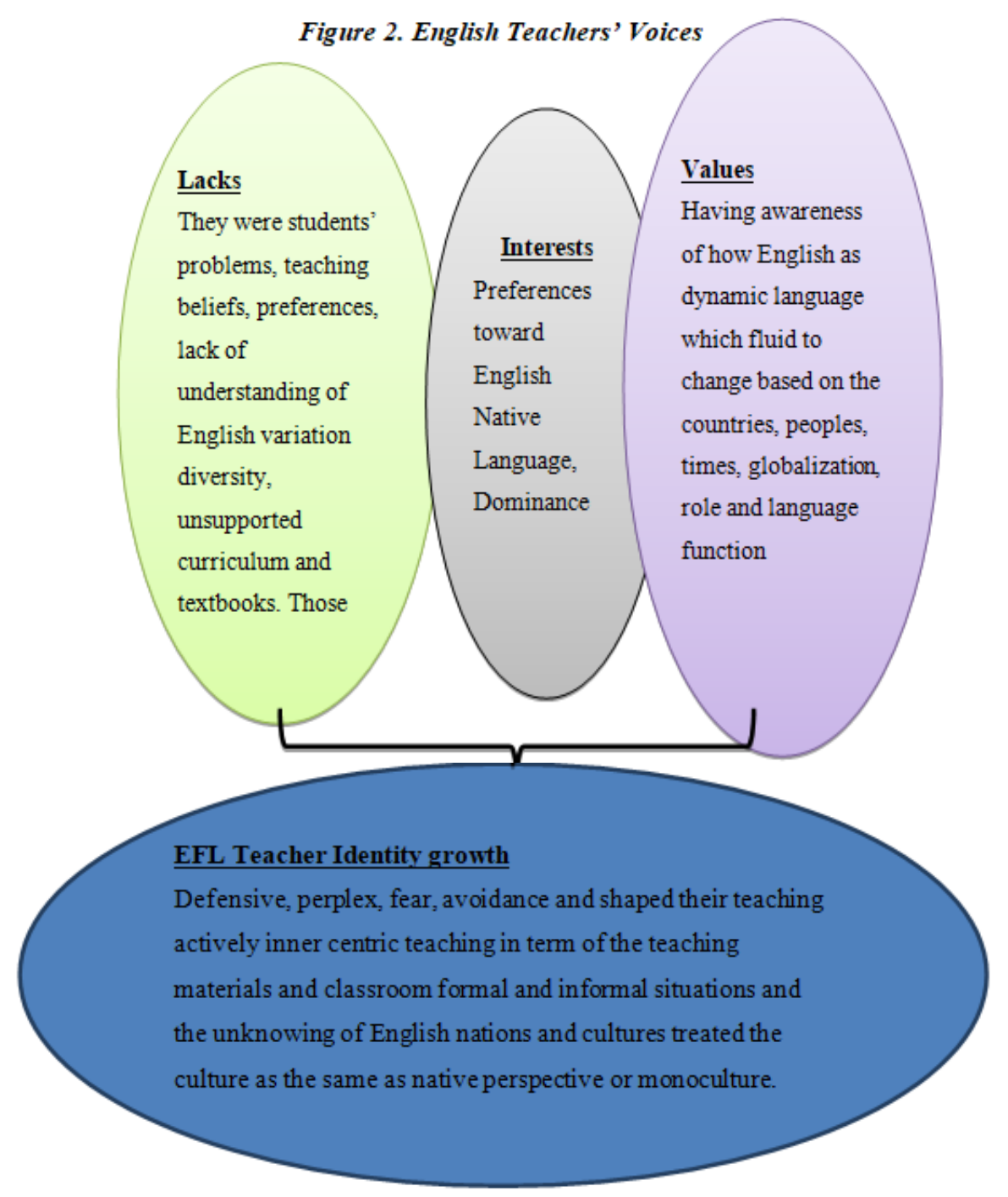

Based on the results showed that, the EFL students' identity and English teachers toward English variations construction in term of their thinking (truth of English, Englishes, dominance), feeling (awareness, Englishes, and racism), and acting (cross cultural interaction, teaching and learning, and leadership management) were various. From the result, it showed that the students were good at learning about and from other culture but when we talked about linguistics parts like their English ability progress, Englishes, actual communication with their international friend, they were hard to accept it or they significantly showed their fear, persistence, their judgment upon themselves and their community, distance, and western centric. This result also supported by Llurda, (2004) most non-native-speaker teachers, both English as second language (ESL) and English as a Foreign Language (EFL) contexts have an adequate level of language proficiency to perform their task. However, if we pause to reflect on the options that lie ahead of them in the new framework of EIL, rather than ESL or EFL, we will see that many teachers in EFL settings (particularly non-native speakers) do not seem to be very sensitive to the new perspectives that are opening up in front of them, and are still 
anchored in the old native-speaker dominated framework in which British or American norms have to be followed and native speakers are considered the ideal teachers. Definitely, it would be happened because they were taught and there was much exposure of Native norm and Standard English.

Therefore, this study suggested emphasizing Nonnative norms more which is more various, common, unique, natural, resources (Jenkins 2003; Kirkpatrick, 2007; McKay, 2002; Sharifian, 2009, 2011). Matsuda (2003) emphasized that we are fail to catch the reality and emphasise the inner-circle English only. We neglects the real linguistic needs of the learners, eclipses their education about the history and politics of English, and fails to empower them with ownership of English (Indonesia English or their tribe English). The limited exposure to English varieties in the classroom may lead to confusion or resistance when students are confronted with different types of English users or uses outside of class. The exposure to different forms and functions of English is crucial for EIL learners, who may use the language with speakers of an English variety other than American and British English. Even if one variety is selected as a dominant target model, an awareness of different varieties would help students develop a more comprehensive view of the English language. Therefore, through this case, we need to help the students to know more English global since that is one of our identities as nonnative English users. If we do not know how our identity also precious we are under colonialization.

\subsection{Pedagogical Implications of EIL Teaching Approach Contribution in Indonesia}

\subsubsection{EIL Teaching Required Change of Mind Set}

After having this oral defense my committee members and my adviser gave suggestions toward my paper that teach me to not only concern on the reflection of how using this teaching method of EIL approach technically but also that is the mindsets (included concerning on the community beliefs and shares empowering community). As they noticed that adopting identity model to see their growth of English nowadays is not merely influenced by adapting EIL approach but there are some factors that influenced their identity growth. That taught me to learn and careful to see the background and behind of English language problem that they brought such as connected to the analyzing hegemony in Indonesia and also be careful to adopt EIL approach in order to bring spring broad for further contribution to enhance the practice of EIL teaching in English education and in actual classroom in Indonesia. The possible reasons could be seen from drawing to the history and to 
mean how English today, and the role of Non-native English teachers, and Educating the General Public.

As I had mentioned earlier that to identify the EFL growth toward English as an international language, it is not merely from adopting EIL approach model, but their identity also tightly connected to the reality that they faced in everyday life such as everyday school life, everyday family life, community, and ideology, culture and tradition power, intelligence (overt and covert) and practices. Those are the structural issues that we might control and influence the EFL learners and teachers' identity that they had and we may not ignore them. Therefore, some of them disagreed with English is theirs but some see English is theirs because of acknowledging the inevitable of English variation. When I tried to look back about their background which is already written and explained in participants information in chapter Methodology included both students (Grade 1 and Grade 2) and English teachers and how this community of this city image and their mainstream school that they had. It is highly connected to what English that they were trying to pursue and mean.

For me, it is the entire story that I already knew and then poured that in my methodology research information. But, the underlying problematic is rather complicated. Those structural arrangements-the basic ways institutions, people, and the modes of production, distribution, and consumption are organized and controlled- dominate teaching and curricula found within them. According to Apple (1990) there are three aspects of the program that need to be articulated at the beginning here: (1) the school as an institution, (2) the knowledge forms, and (3) the educator him or herself. Each of this must be situated within the larger central of relations of which is constitutive part. He tries to elaborate that place the knowledge that we teach, the social relation that dominate classrooms, the school as a mechanism of cultural and economic preservation and distribution, and finally, ourselves as people who work in this situation, back into the context which they all reside. Those structural relations 'determine' these three aspects of schools. As Apple argues, one of the keys to understanding this is the concept of hegemony.

Raymond William's discussion of hegemony, a concept most fully developed in the work of Antonio Gramsci, provides an excellent summary of these points (cited in Apple, 1990). 
"For hegemony supposes the existence of something which is truly total, which is not merely secondary or superstructure, like the weak sense of ideology, but which is lived at such a depth, which saturates the society to such an extent, and which, as Gramsci put it, even constitutes the limit of commonsense for most people under its sway, that it corresponds to the reality of social experience very much more clearly than any notions derived from the formula of base and superstructure.

For if ideology were merely some abstract impose notion, if our social and political and cultural ideas and assumptions and habits were merely the result of specific manipulation, of a kind of overt training which might be simply ended or withdrawn, then the society would be very much easier to move and to change than in the practice it has been or is. This notion of hegemony as deeply saturating the consciousness of a society seems to be fundamental" From this explanation, we found that hegemony is real superstructure and also specific manipulation that deeply influenced immerse in society consciously and unconsciously. Those ideas does not mean that we were defeated to these real situations that the students and English teachers faced, we could see the oppressed of pedagogy or firming to the singularity of learning English, Standard and rigid learning English that made them to be slaved and willing or not willing manipulated them. This is the initial resources that we could prepare to design the situated English curriculum which not ignore their future and real struggling that they face in learning and teaching and see where to start to fix and reconstruct them. These following paragraphs are some ways to be considered and then solved step by steps based on the students and English teacher' cases toward these hegemony concepts.

\subsubsection{Understanding EIL Model}

It is important to prepare well how to adopt this model in teaching learning process carefully which start from giving the students the history of English and Indonesia or tribe English and to mean how English today in the classroom critically, and the role of Non-native English teachers, and Educating the General Public authentically. Without carefully equipping and sharing some of these parts, it just shows the progressive learning education but still remains the one of important things of English, respecting their own English language and nation English language and peace to the variation of English international nowadays. 


\subsubsection{The History and English Today}

A curriculum that teaches EIL must address the colonial past (the postcolonial present) of the language and the power inequality associated with its history (Pennycook, 1998). The teaching of EIL is linked to the stories of its worldwide spread; its changes in forms, functions, and users; and the politics of the language. In other words, EIL is not a neutral possession of those of the inner circle to be learned according to their norms, but a topic of study itself, consisting of examples of diversity of functions (Kachru, 1992), togetherness with indigenous languages, use as the medium of education or language of law, service as the vehicle for international communication, and change through nativization. Without the awareness of such potential power and struggles of the colonial past, learners may internalize a colonialistic view of the world (Pennycook, 1998) and devalue their own status in international communication. Critical awareness of the power inequity that the language's colonial past may imply and that the users of EIL may need to deal with English today.

In order to know how English today is, we could ask essential curricular questions about English critically. What do we know about English? what do we need to learn about English? How do you want to be a good English user? questions to draw out this awareness of English in daily experience could be can you give example of people you know who use English? what English do you see at work, at home, on TV, or in the hand phone? who uses English in our society for what purpose? how are we going to learn it? English teachers should see English subject as inter disciplinary learning. Judy (1980, p. 75) "English is not just literature and grammar". It is math, sport, psychology, history, physics, biology, chemistry, econimics, art, entertainments, and so on. Teaching English is one of subject that can present in an open classroom nowadays.

\subsubsection{Empowering Nonnative English Teachers and General Public}

In Asia context, this issue is highlight and there are multitude researches comparing about Native English-Speaking Teachers (NESTs) and Non-native EnglishSpeaking Teachers (NNESTs).

This is supported by Madrid and Cañado (2004) it remains that the native-nonnative issue still high trend interest in the field of ELT and a lot of studies have been 
conducted into the matter. There are not few researches also led to debate both NEST and NNEST hierarchically. Those of them put superior image for NESTs and inferior for NNESTs in term of their teaching behaviour, competence, accents, pedagogy, etc. (Braine, 2010). There is a popular term assumed that NNESTs and NESTs are "two different species". (Árva and Medgyes, 2000; Medgyes, 2001). It is not important anymore to emphasize the status of NESTs and NNESTs. According to Lazaraton, (2003) "Identity is not omnirelevant..." All English Second Language (ESL)/ English as foreign language (EFL) teachers may be classified by means of age, gender, race, teaching experience, and sexual orientation. But what have to concern now is empowering and maintaining the potential of English teachers (Lazaraton, 2003; Seidlhofer, 1999) especially in Indonesia. Since English is widely accepted as an international language. It enables teachers to share ideas and cultures with others across the globe. Starting this point, teaching English paradigm needs to focus on facilitating intercultural communicative competence in multilingual and multicultural contexts. An understanding of the role of Nonnative English teachers in shaping the future of English is essential for EIL users.

It is clearly seen from my English teacher interviewees especially who still novice teachers or young English teachers who have still long journey to educate the young generations. They said that they had never heard this teaching approach in their bachelor degree that made them have no idea about it. It was not be taught either when I was in trained English teacher. To incorporate Englishes in English language teaching, teachers themselves. Programs for preservice EFL teachers tend to focus on the inner circle and would benefit greatly from incorporating with EIL perspective. Additionally, preservice teachers who are not Native Speakers should have the opportunity to reflect on their own strengths as Non-native English teachers, and these issues should be discussed among all students.

Moreover, out of English teachers, administrators, and the public including students and their parents need to help to be aware of the general public's attitudes toward English varieties and possible resistance and also take actions to address any concerns they may have. 
One of the ways, I think already addressed by Miss Hasni while discussing EIL perspective at the very beginning of our interview, she shared that it was good to introduce nation English and nonstandard English as good and valid English to students and teachers at the ceremony that they have on every Monday. Moreover, the responds of students voice about how their external problems of learning English is influenced by mocker from their friends or community. It is good to educate general public about this global English such as making conference days, open-campus days for prospective students, or Parent Teacher Association meetings, where administrators and teachers can discuss curriculum strengths and innovations. These opportunities can be used to explain that incorporating English as an international language which adds to the current repertoire and thus enrich the curriculum. Parents and other communities are more likely to be supportive if they are better informed about the spread of English and convinced that changes are good for their children and communities.

\section{CONCLUSION}

The reflection of this study is beginning with the assumption of not only seeing English as international language, but also as local language that Indonesians would need to use in daily lived. Furthermore, I ignored that school often select socially privileged class interest and knowledge for everyone. Limited understanding of what that means by stating English as international and local language for everyone. Pierre Bourdieu in his book Reproduction in education, society, and culture (1977) which shares about cultural capital, social capital and taste that what matters to learn in school is randomly selected by social elite. Some knowledge is considered as important for everyone is based on the upper-class flavor and interest. When we connected to the statement of English is for everyone is a value that represents more privileged groups' interest. In other words, what is important to learn in the class, gender, and cultural based. In farm, what is needed to learn is different from cities. To tribal kid and adults, what is important for everyone to learn? English may not be on the top list even though school may emphasize it. Is everyone needs to learn or good to learn? With such assumption, when students show no interest to learn might identify his or her lack of interest, lack of motivation. However, this is very English-centric perspective. 
I had not considered that there are people in this world who do not care about learning English. Moreover, I am not aware of the possibilities that some students coming from different background may have different interest and aspiration for their lives and that is not a problem.

As an English teacher, how do we understand such way of life in which English is not a significant component in people's life? I should not identify such lack of learning or using English as problematic attitude. If I think that all youngsters need to and should love to learn English as their own mother-tongue language, that's why English becomes hegemonic language. What is important to learn may be different from what school choose for them. Because I was not aware of such possibility could exit, I did not have arrangement for further discussion with students who show very little interest in grade two class. To further understand their interest and aspirations for their lives. In other words, I suggested that teachers need to improve their curriculum design and teaching methods without asking and knowing what students are really interest to learn in their lives. The other limitation, it was done within one month for five meetings with three topics and with small participants, two classes and two English teacher partners. It would be useful to do it in a longitudinal study to implement massive exposures and media to see the process and we could better understand what kind of challenges, strategies, English teachers' encounters both professional and novice English teachers and extending classes to do inquiry such lifted questions and problems exist that had been stated above.

\section{REFERENCES}

Apple, M. W. (1990). Ideology and curriculum. New York: Routledge.

Braine, G. (2010). Nonnative Speaker English Teachers: Research, Pedagogy, and Professional Growth. New York: Routledge.

Hino, N. (2012). Endonormative models of EIL for the expanding circle. In In A. Matsuda (Ed.), Principles and practices of teaching English as an international language (pp. 2842). Bristol: Multilingual Matters.

Kachru, B. B. (1992). World Englishes: Approaches, issues and resources. Language Teaching 25: $1-14$.

Lazaraton, Anne. (2003). Incidental Displays of Cultural Knowledge in the Nonnative-English Speaking Teacher's Classroom. TESOL QUARTERLY. Vol. 37, No. 2, Summer 2003

Madrid, D. and Cañado, M., L., P. (2004). Teacher and Student Preferences of Native and Nonnative Foreign Language Teachers. PORTA LINGUARUM 2. 
Matsuda, A. (2019). World Englishes in English language teaching: Kachru's six fallacies and the TEIL paradigm. World Englishes, 38(1-2), 144-154.

Medgyes, P. (2001). When The Teacher is a Non-Native Speaker. In M. Celce-Murcia (Ed.), Teaching English as a second or foreign language, Third edition (pp. 415-428). Boston: Heinle \& Heinle.

Pennycook, A. (1998). The right to the language: Toward a Situated Ethics of Language. London and New York: Longman

Selvi, A. F. (2014). Myths and misconceptions about the non-native English speakers in TESOL (NNEST) Movement. TESOL Journal,5(3),573-611.

Seidlhofer, B. (1999). Double standards: Teacher education in the Expanding Circle. World Englishes, 18, 233-245. International Journal of Applied Linguistics, 11, 133-158.

Widdowson, H.G. (1995) Discourse analysis: A critical view. Language and Literature; 4 (3): $157-172$. 